\title{
Challenges and Opportunities on Elucidating Irradiated Fuels with Atom Probe Tomography
}

\author{
Mukesh Bachhav ${ }^{1}$, Jian Gan ${ }^{1}$, Lingfeng $\mathrm{He}^{1}$, Brandon Miller ${ }^{1}$, and Dennis Keiser ${ }^{2}$ \\ 1. Advanced Characterization Division, Idaho National Laboratory, Idaho Falls, ID, USA \\ 2. Nuclear Fuels and Materials Division, Idaho National Laboratory, Idaho Falls, ID, USA
}

Fuel materials used in nuclear reactors are subjected to extreme conditions during their operation and storage resulting in microstructural changes. It is therefore critical to understand microstructural evolution in nuclear materials and correlate with their performance. One of the main mechanisms in guiding the microstructural changes of fuels is damage associated with the formation and migration of fission products [1-2]. For instance, the formation and the movement of fission product leads to void formation and grain boundary segregation which can promote integrity loss of the fuel [3-4]. Also, during irradiation at aggressive reactor conditions, interaction can occur between the fuel particle and the matrix in a dispersion fuel that results in development of an interaction layer that is unstable under irradiation, which can contribute to fuel plate failure [3-4]. Thus, it is desirable to access the microstructural information in irradiated fuels in order to understand migration of fission product and their affect on performance of fuels.

Atom Probe Tomography (APT) is an unique technique to provide 3D distribution of microstructures in materials at nano length scale along with near accurate chemistry mapping of the elements. However, there has been limited APT work done in past to analyze irradiated metallic and oxide fuels for correlating microstructure with the performance of fuel.

APT is employed in current study to elucidate microstructural changes in fuel and to quantify fission products formation after irradiations. Systematic APT study is carried out on UMo alloy fuel particles [3] coated with a diffusion barrier layer of $\mathrm{ZrN}$ and dispersed in Al matrix. APT analysis on irradiated U-Mo fuel reveals uniform distribution spherical shaped clusters enriched with fission products such as $\mathrm{Ru}, \mathrm{Pd}$, $\mathrm{Cd}, \mathrm{Ag}, \mathrm{Xe}, \mathrm{Pr}, \mathrm{Nd}$ etc. Quantification and distribution of fission products relied on running conditions of APT instrument (base temperature, pulse rate, detection rate, laser and mode of operation). Low base temperature $(\mathrm{T}=20 \mathrm{~K})$ and voltage mode during APT analysis offered better spatial resolution and quantification for fission products formed in irradiated U-Mo fuel (shown in Figure 1 and Table 1). Transmission Electron Microscopy (TEM) analysis offered high-resolution images of bubbles along with distribution of U, Xe and Mo (shown in Figure 2).

While APT might offer very high chemical and spatial resolution that no other technique can match [5], challenges remain for multicomponent materials and interfaces in terms of chemical and spatial resolution. For instance, the so called local magnification effect is a well-known artifact arising from differences in evaporation fields of adjacent phases. These differences can lead to ion trajectory overlaps near the interface and loss of spatial resolution. Comparison between the experimental data and the simulation results using be presented and discussed.

\section{References:}

[1] A. Leenaers et al, J. Nucl. Mater. 335 (2004), p. 39.

[2] J. Gan et al, J. Nucl. Mater. 396 (2010), p. 234. 
[3] D. Keiser, J. Nucl. Mater. 458 (2015), p. 406.

[4] F. Mazaudier, C. Proye, F. Hodaj, J. Nucl. Mater. 377 (2008), p. 476.

[5] B. Gault et al, Materials Today 15 (2012), p. 378.

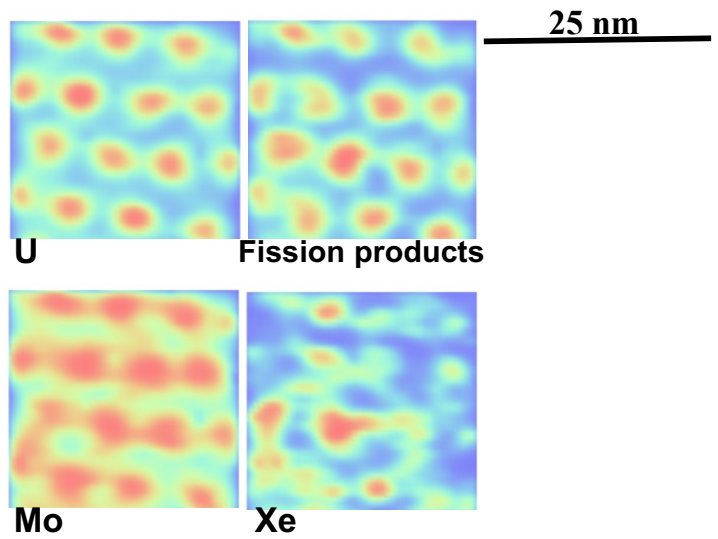

Figure 1. 2 D density map of U, Mo and fission products and Xe obtained from irradiated U-Mo fuel in APT. Dimension of the box: $25 \mathrm{~nm}$ X $25 \mathrm{~nm}$ X $5 \mathrm{~nm}$.

Table 1. Measured composition from U-Mo metallic fuel obtained in APT.

\begin{tabular}{|c|c|}
\hline Elements & At. \% \\
\hline U & 63.3 \\
\hline Mo & 28.1 \\
\hline Fission Products & 7.2 \\
\hline Xe & 1.3 \\
\hline
\end{tabular}

(a)

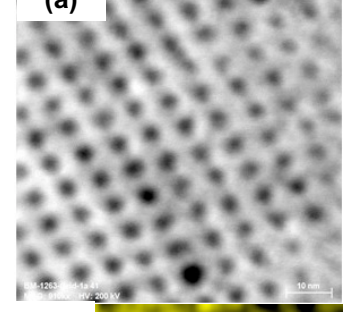

(c)

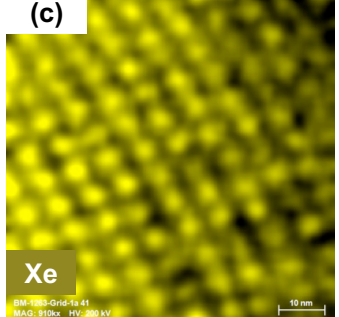

(b)

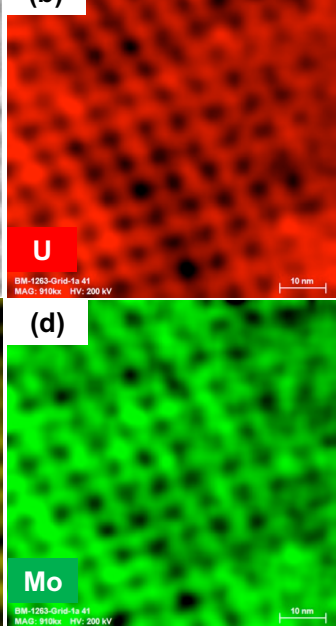

Figure 2. (a) HAADF image of the irradiated U-Mo fuel (b-d) Corresponding EDS map for U, Xe and Mo. 